\title{
Artificial Neural Network Applied to Estimate the Power Output of BIPV Systems
}

\author{
A.J. Aristizábal \\ Departamento de Ingeniería, Universidad de Bogotá Jorge Tadeo Lozano, Bogotá, Colombia
}

\begin{abstract}
This paper presents an artificial neural network (ANN) model to estimate the power generated by integrated photovoltaic systems in buildings - BIPVS. The model has as primordial variables, the solar radiation and the ambient temperature of the site of installation of the photovoltaic generator and integrates secondary variables such as the zenith solar angle and the azimuth solar angle. The artificial neural network consists of three layers of operation that allows to adapt to the behavior of the environmental and electrical variables of the photovoltaic generator to create output variables of electrical power through daily profiles.

The neural network was implemented in the software Matlbab ${ }^{\mathrm{TM}}$ and it was validated using the actual data of monitoring of a $6 \mathrm{~kW}$ BIPV system installed at Universidad de Bogotá Jorge Tadeo Lozano, in Bogotá, Colombia. The results indicate a correlation coefficient of $98 \%$ on the output power of the BIPV system between the artificial neural network and the performance data of the solar photovoltaic plant. These results show the reliability of the model for PV systems operating in different climatic conditions and different generation capacities.
\end{abstract}

Keywords: Photovoltaic systems, artificial neural network, power output, BIPVS modelling.

\section{Introduction}

In 2015 , some $60 \mathrm{GWp}$ of new photovoltaic (PV) systems were installed globally [1] bringing the total worldwide installed capacity to nearly $250 \mathrm{GWp}$, with Asia leading the wave of new installations [2]. Information Handling Services Inc. (HIS) has raised its global solar PV forecasts for 2016-65 GWp, and over $70 \mathrm{GWp}$ is expected to be installed in 2019 [3]. By 2020, the cumulative global market for solar PV is expected to triple to around $700 \mathrm{GWp}$ [4].In addition to being a renewable and pollution free energy genration technology with no moving parts, PV modules can also be integrated into buildings as BIPV systems, adding aesthetic value [5]. When installed in an optimized way, BIPV systems can reduce heat transferred through the envelope and reduce cooling load components decreasing the $\mathrm{CO} 2$ emissions [6]. Apart from some facade installations, the rooftop segment represented more than $23 \mathrm{GWp}$ of total installations in 2015, with projections of more than 35 GWp to be installed by 2018 [2].

A variety of circuit-based models, such as single diode model and double diode model, have been proposed to describe the I-V characteristics of a PV module [7-11]. The former techniques usually employ simplified formulas and information provided by the PV module manufacturer [12-14]. Hence, these techniques are easy to implement but more vulnerable to the accuracy of the few available data points. The latter techniques, including neural network [15,16], differential evolution (DE) [17], genetic algorithm [18], and particle swarm optimization (PSO) [19], etc., usually employ all the experimental data at various operating conditions to extract physical parameters, thus providing a higher confidence level of the extracted parameters. There are several studies about photovoltaic energy in Colombia [20-24] and this one is intended to improve the distributed energy analysis on buildings. This article describes a $6 \mathrm{~kW}$ BIPV system installed at Universidad de Bogotá Jorge Tadeo Lozano in Bogotá, Colombia and a mathematical model is proposed through the implementation of an artificial neural network to estimate the output power of the photovoltaic system. The remainder of the paper is organized as follows. Section II introduces the PV system and the database used and the basic knowledge of ANN. The experimental results and quantitative results are in Section III. This is followed by conclusions in Section IV.

\subsection{BIPV System and Database}

\section{Methodology}

The grid-connected BIPV system installed at the Universidad de Bogotá Jorge Tadeo Lozano includes a PV-array of 24 modules of poly-crystalline silicon (Trina Solar TSM-PA05.08), each one of $250 \mathrm{Wp}$ and an inverter Sunny Boy 5000-US model of $5000 \mathrm{~W}$. Taking into account that the DC input of the SB 5000-US inverter varies between $175 \mathrm{~V}$ and $480 \mathrm{~V}$ and the voltage at maximum power point (VMPP) of the module is $38 \mathrm{~V}$, the PV array was built interconnecting 2 branches in parallel of 12 modules in series each one. Under these conditions the nominal power of the PV array is $6000 \mathrm{Wp}$. 
The PV system is fully monitored to evaluate and analyze the performance and the power quality of the BIPV system.

Fig. 1 shows a sketch of the whole system, including the monitoring system.

The monitoring system was developed using Virtual Instrumentation and it includes a unit for measuring the power quality parameters because the power quality standards set by the utility companies for decentralized power plants must be fulfilled in order to prevent overstressing the equipment in the distribution grid. Independent power producers, who want to sell electricity to utility companies, must accomplish these standards.

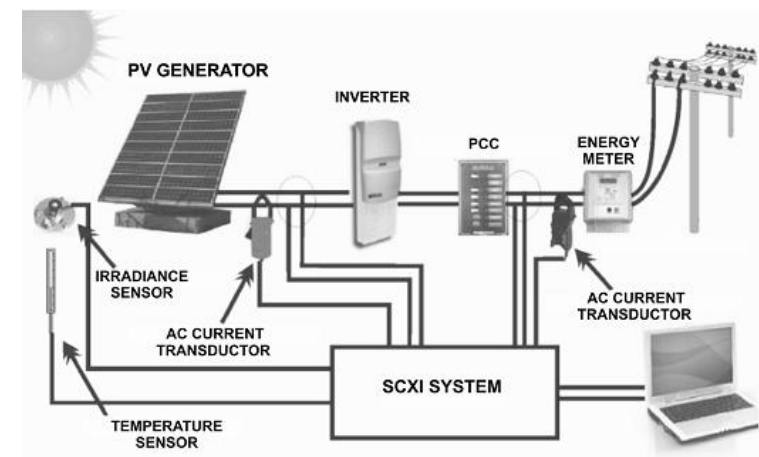

Fig. 1.Overview of the grid-connected BIPV system and the devices of the monitoring system.

This monitoring system creates the necessary database for use in the proposed artificial neural network. Saved variables are: solar radiation, ambient temperature, DC current and voltage, and AC voltage and current. The monitoring system saves 1 data per minute of each variable; between 5 am and $7 \mathrm{pm}$. Files are saved in .xls format on a daily basis. Solar zenith angle and solar azimuth angle are derived from time of day and day of year by using the solar position algorithm developed by NREL.

The 12-month (2016) monitoring data are used to train our model and perform performance testing.

\subsection{Artificial neural network model (ANN)}

A typical feedforward neural network is depicted in Fig. 2:

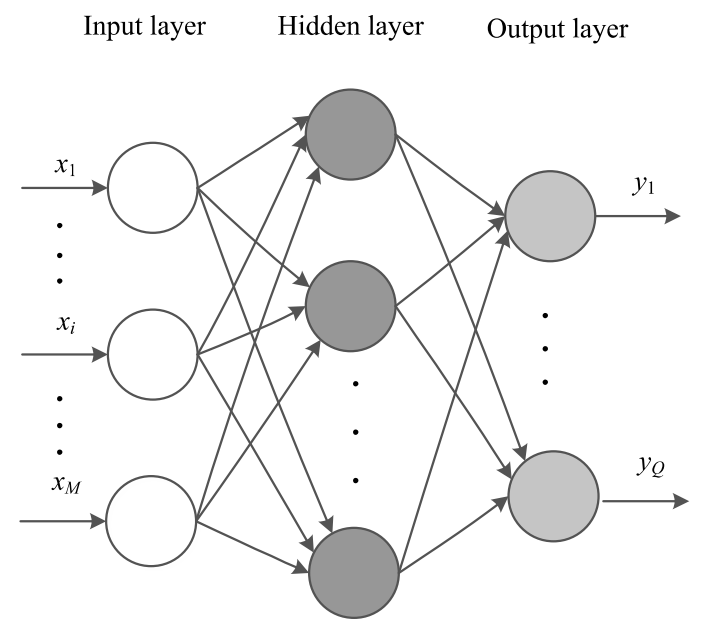

Fig. 2. Basic model of an artificial neural network [25].

This neural network can be used to fit any kind of finite input to output mapping problem with enough neurons in the hidden layer. The input layer accepts inputs of an M-dimensional vector, X; the hidden layer, $\mathrm{H}$, is composed of N neurons; and the output layer, Y, has Q outputs. The connection between layers follows [25]:

$$
\begin{aligned}
& h_{j}=f_{H}\left(\sum_{i=1}^{M} x_{i} \omega_{i, j}+b_{j}\right), \text { for } j=1, \ldots, N \\
& y_{q}=f_{Y}\left(\sum_{j=1}^{N} h_{j} \omega_{j, q}^{\prime}+b_{q}^{\prime}\right), \text { for } q=1, \ldots, Q
\end{aligned}
$$

where $x i, h j$, and yq are, respectively, the ith input element, the jth output of the hidden layer, and the qth 
element of the output layer; ui,j is the weight from ith input element to the jth neuron of the hidden layer, and $\mathrm{u} 0 \mathrm{j}, \mathrm{q}$ is the weight from jth neuron of the hidden layer to the qth neuron of the output layer; bj and b0q are the biases of the jth neuron of the hidden layer and qth neuron of the output layer, respectively; fH and fY are the transfer functions for the hidden layer and the output layer, respectively.

This model is used to estimate PV power output from environmental information.

Before training the network, the input and output data sets are normalized to $[1,1]$ according to the following expression:

$v=v_{\min }+\frac{u-u_{\min }}{u_{\max }-u_{\min }}\left(v_{\max }-v_{\min }\right)$

where $\mathrm{u}$ is the original data falling in the interval [umin, umax], and $\mathrm{v}$ is the corresponding normalized value in the interval [vmin, vmax].

The commonly used hyperbolic tangent sigmoid function and linear function are used as the transfer function of the hidden layer and output layer, respectively. The tangent sigmoid function is defined as [25]:

$$
\tan \operatorname{sig}(s)=\frac{2}{1+\exp (-2 s)}-1
$$

where s represents the net input of a neural network node.

The Levenberg-Marquardt (LM) algorithm, a widely used back- propagation algorithm for supervised learning, is employed to update the network weights and biases in the following way:

$\mathbf{w}_{k+1}=\mathbf{w}_{k}-\left(\mathbf{J}^{T} \mathbf{J}+\mu \mathbf{I}\right)^{-1} \mathbf{E}$

where wk is the vector of weights and biases at step $\mathrm{k}, \mathrm{J}$ is the Ja- cobian matrix of the network error E with respective to weights and biases, JT is the transpose of matrix $\mathrm{J}$, I is the identity matrix, and $\mathrm{m}$ is the damping parameter of the LM algorithm.

\section{Results And Discussion}

The model was developed in Matlab and the program creates an .xls file with the results. The meteorological information to train the neural network corresponds to a year of data of solar radiation and ambient temperature acquired by the system of monitoring during 2016. Using the described neural network, it is possible to model the behavior of the dc-ac power or any other variable of the BIPV system. The model data are then validated with the data measured by the monitoring system. After performing the respective tests, it was found that with 12 neurons it is enough to estimate the power using four inputs: solar radiation, ambient temperature, azimuth angle and zenith angle. The neural network was trained using the group of measured data of the whole year 2016: one data per minute for 365 days (between 5 am and 7 pm; daily).

Fig. 3 shows the results of the model applied to the ac power of the BIPV system for October 28, 2016.

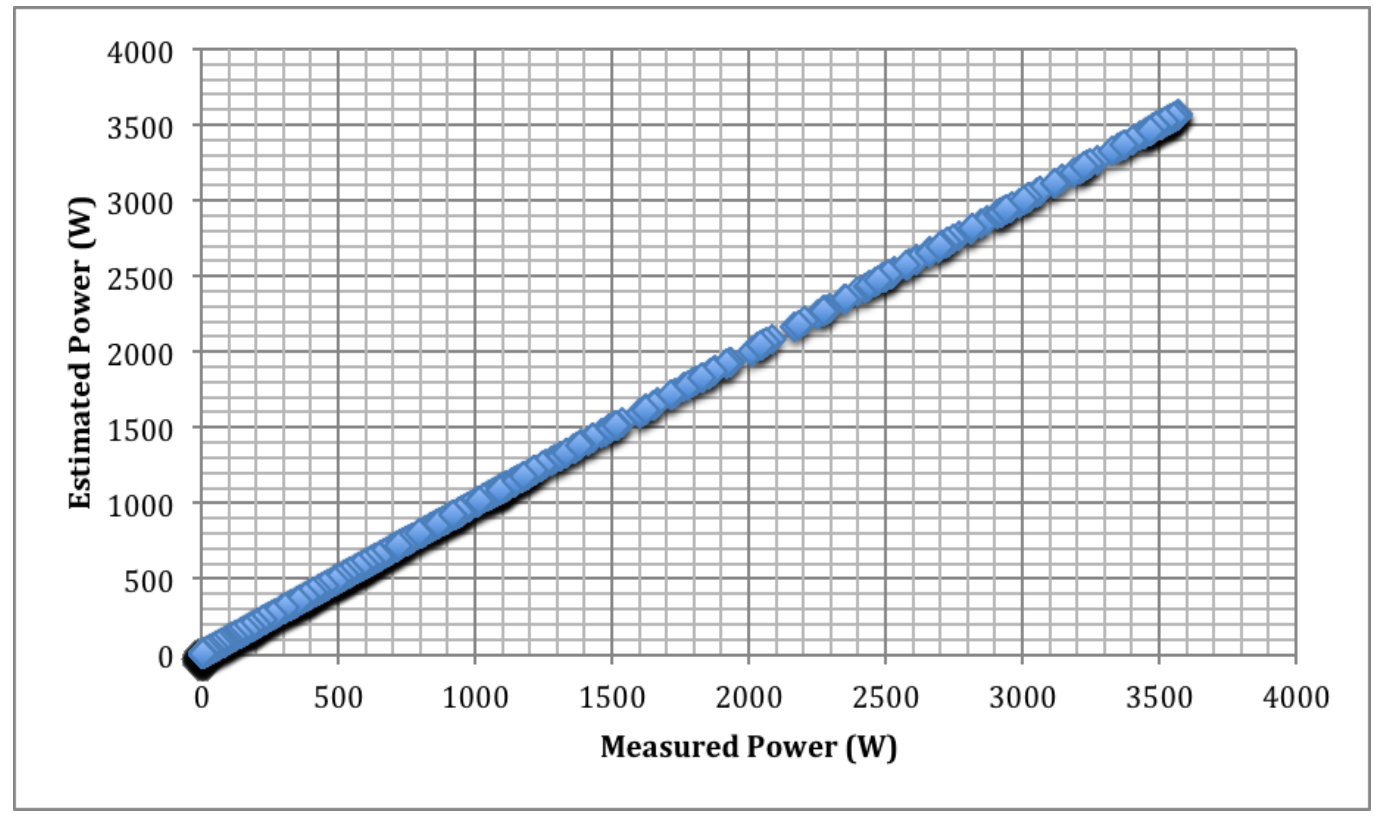

Fig. 3.Estimated versus measured power on testing dataset for the BIPV system. 
The day analyzed was characterized by high cloudiness and rain that did not allow the inverter to reach a value close to its nominal power of $5000 \mathrm{~W}$. The maximum power generated by the inverter was $3600 \mathrm{~W}$. The ac power estimated by the neural network has an approximation of $98 \%$ in comparison to the ac power measured by the monitoring system.

Fig. 4 shows the results of the neural network to estimate the power of the pv generator for September 12, 2016.

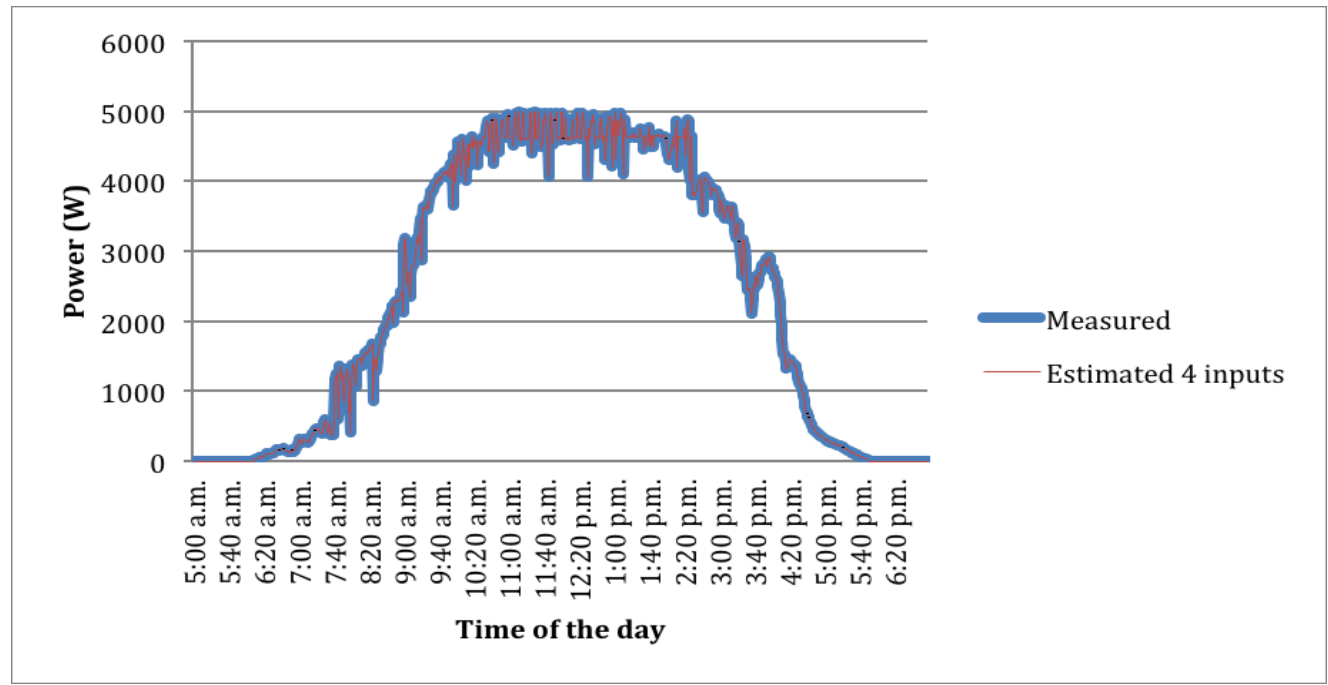

Fig. 4.DC power estimated by the artificial neural network with 4 inputs and dc power measured for Sept. 12, 2016.

The solar system begins to produce power around 6:16 am and lowers its production near $5 \mathrm{pm}$. In this case the neural network estimates a dc power with an accuracy of 98,5\% in comparison to the power measured by the monitoring system. As can be seen, the highest power generation is between 10 am and 3 pm with values above $4000 \mathrm{~W}$.

Fig. 5 shows the analysis performed for November 11, 2016 with 2 inputs in the neural network: solar radiation and temperature.

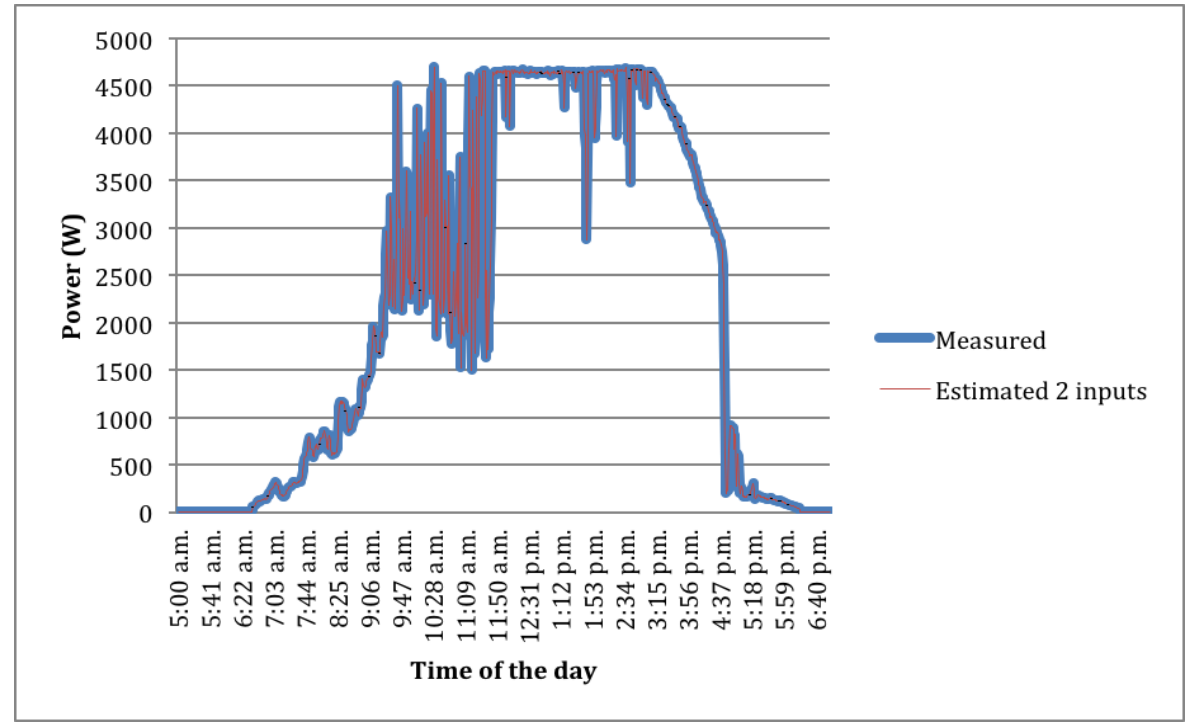

Fig. 5. DC power estimated by the artificial neural network with 2 inputs and de power measured for November $11,2016$.

In this case, the BIPVS system starts its dc power production at 6:22 am and ends at $6 \mathrm{pm}$. It is possible to observe a period of cloudiness and rain between 9:30 am and 11:50 am. The greater power reaches the 4600 $\mathrm{W}$. The correlation between the estimated power and meaured power was 97.6\%. Finally, the artificial neural network is evaluated by estimating the dc power and ac power produced by the BIPV system. The results are shown in Fig. 6. 


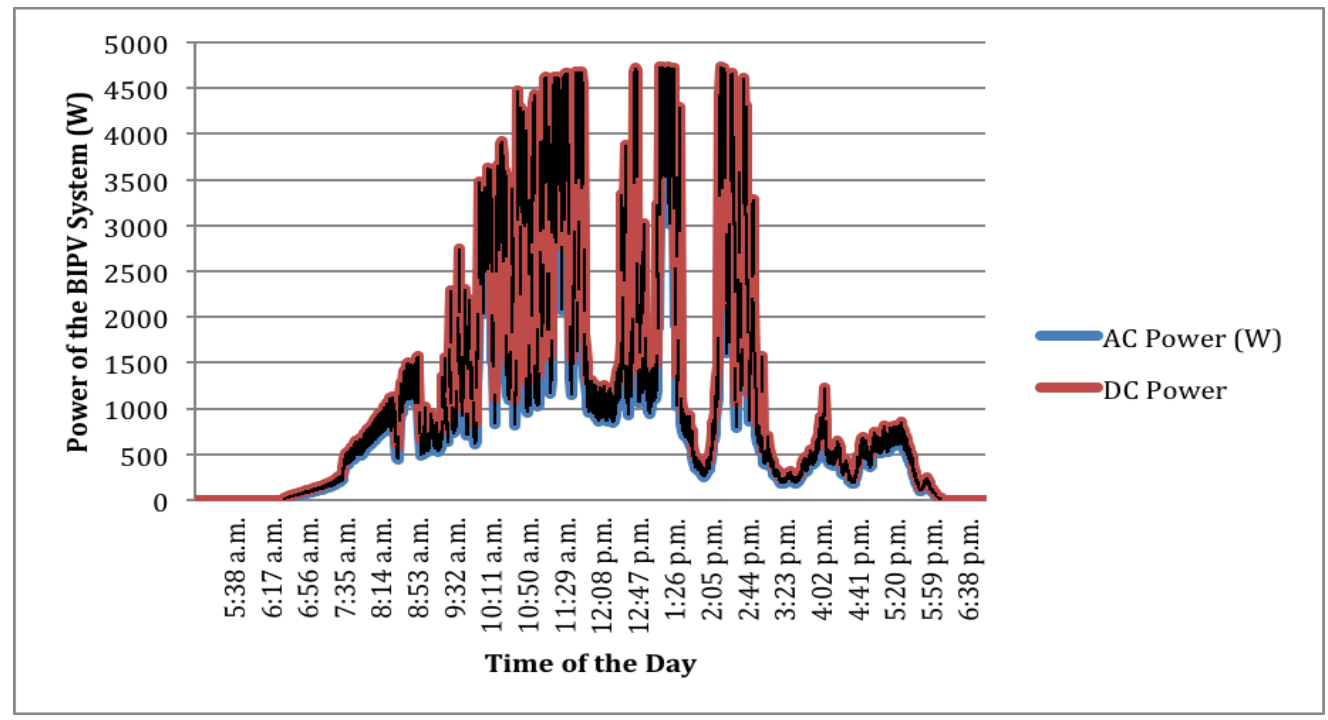

Fig. 6. DC and AC power estimated by the artificial neural network with 4 inputs for December 2, 2016.

The black area of Fig. 6 represents the difference in power between the dc and ac power of the BIPV system. In other words, it is the inverter losses in the dc-ac power transformation process. When validating these results with those obtained by the monitoring system, there is a correlation of $98 \%$. The inverter in this case achieved an efficiency of $92 \%$. The 12 neurons used in this case have the capacity to estimate the result with a deviation coefficient of 0,18 .

\section{Conclusions}

The artificial neural network presented, is a useful tool that could be applied to predict the power generated by BIPV systems. The correlation coefficient of $98 \%$ allows to guarantee the accuracy in the estimation of the power of the system. A total of 12 neurons were sufficient to estimate the power with a good degree of accuracy. It was found that a larger number of neurons did not provide a significant improvement in accuracy. The amount of data to train the artificial neural network is a key point to achieve a good degree of accuracy in power estimation. In our case, we had data for a full year and it is recommended to have at least 6 months of information data to ensure a good degree of accuracy in the estimation. Thanks to the reliability of the artificial neural network and the availability of the data, it is possible to apply the same study to any BIPV system variable: energy, photo-generated current and dc-ac voltaje. In this article we used computational tools that strengthen the performance analysis of BIPV systems: virtual instrumentation to carry out the monitoring of the pv system and Matlab to implement the artificial neural network.

\section{Acknowledgements}

This work was carried out with the financial support of the researching project 633-11-14 from Universidad de Bogotá Jorge Tadeo Lozano.

\section{References}

[1]. M. Osborne, IHS remains cautions on PV market demand growth, in: PV-Tech, PV-Tech, London, 2015.

[2]. EPIA European Photovoltaic Industry Association, Global Market Outlook for Photovoltaics 2014 - 2018 , Brussels, Belgium, 60 p. (2014).

[3]. B. Beetz, IHS increases 2015 PV forecast to 59 GW, 2016 to 65 GW, in PV Magazine Photovoltaic Markets \& Technology (2015). Accessed in February, 2016. Available at http://www.pv-magazine.com/news/details/beitrag/ihs- increases-2015-pv-forecast-to-59gw-2016-to-65-gw 100021513/ \#axzz45C8rLdVq.

[4]. GTM, Global PV Demand Outlook 2015-2020: Exploring Risk in Downstream Solar Markets (2015). Accessed in January, 2016. Available at https://www. greentechmedia.com/research/report/global-pv-demand-outlook-2015- 2020.

[5]. D. Prasad, M. Snow, Designing with Solar Power - A Source Book for Building Integration Photovoltaics (BiPV), Images Publishing, Australia, 2002.

[6]. M.S. ElSayed, Optimizing thermal performance of building integrated photovoltaics for upgrading informal urbanization, Energy Build. 116 (2016) 232-248.

[7]. T. Ikegami, T. Maezono, F. Nakanishi, Y. Yamagata, K. Ebihara, Estimation of equivalent circuit parameters of PV module and its application to optimal operation of PV system, Sol. Energy Mater. Sol. Cells 67 (1-4) (2001) 389e395.

[8]. A.N. Celik, N. Acikgoz, Modelling and experimental verification of the operating current of mono-crystalline photovoltaic modules using four- and five- parameter models, Appl. Energy 84 (1) (2007) 1-15.

[9]. J.D. Mondol, Y.G. Yohanis, B. Norton, Comparison of measured and predicted long term performance of grid a connected photovoltaic system, Energy Convers. Manag. 48 (4) (2007) 1065-1080.

[10]. K. Ishaque, Z. Salam, H. Taheri, Simple, fast and accurate two-diode model for photovoltaic modules, Sol. Energy Mater. Sol. Cells 
95 (2) (2011) 586-594

[11]. K. Ishaque, Z. Salam, H. Taheri, Syafaruddin, Modeling and simulation of photovoltaic (PV) system during partial shading based on a two-diode model, Simul. Model. Pract. Theory 19 (7) (2011) 1613-1626.

[12]. M.G. Villalva, J.R. Gazoli, E. Ruppert, Comprehensive approach to modeling and simulation of photovoltaic arrays, Ieee T Power Electr. 24 (5-6) (2009) 1198-1208

[13]. Y. Mahmoud, W. Xiao, H.H. Zeineldin, A simple approach to modeling and simulation of photovoltaic modules, Ieee T Sustain Energ 3 (1) (2012) 185-186.

[14]. R. Chenni, M. Makhlouf, T. Kerbache, A. Bouzid, A detailed modeling method for photovoltaic cells, Energy 32 (9) (2007) 17241730 .

[15]. F. Bonanno, G. Capizzi, G. Graditi, C. Napoli, G.M. Tina, A radial basis function neural network based approach for the electrical characteristics estimation of a photovoltaic module, Appl. Energy 97 (2012) 956-961.

[16]. E. Karatepe, M. Boztepe, M. Colak, Neural network based solar cell model, Energy Convers. Manag. 47 (9-10) (2006) 1159-1178.

[17]. K. Ishaque, Z. Salam, An improved modeling method to determine the model parameters of photovoltaic (PV) modules using differential evolution (DE), Sol. Energy 85 (9) (2011) 2349-2359.

[18]. M. Zagrouba, A. Sellami, M. Bouaicha, M. Ksouri, Identification of PV solar cells and modules parameters using the genetic algorithms: application to maximum power extraction, Sol. Energy 84 (5) (2010) 860-866.

[19]. L. Sandrolini, M. Artioli, U. Reggiani, Numerical method for the extraction of photovoltaic module double-diode model parameters through cluster analysis, Appl. Energy 87 (2) (2010) 442-451.

[20]. A. Chica, F. Rey and J. Aristizábal. Application of autoregressive model with exogenous inputs to identify and analyse patterns of solar global radiation and ambient temperature. International Journal of Ambient Energy 2012; 33 (4): 177-183.

[21]. Aristizábal J, Gordillo G. Performance and economic evaluation of the first grid - connected installation in Colombia over 4 years of continuous operation. International Journal of Sustainable Energy 2011; 30(1): 34-46.

[22]. Banguero E, Aristizábal J. and Gordillo G. Performance and economic evaluation of the first grid - connected installation in Colombia over 4 years of continuous operation. International Journal of Sustainable Energy 2011; 30(1): 34-46.

[23]. D.C. Sierra, A.J. Aristizábal and J.A. Hernandez. Lyfe cycle assessment applied to photovoltaic energy a review. Journal of Electrical and Electronics Engineering 2016; 11 (5): 6-13.

[24]. A.J. Aristizabal. Virtual instrumentation applied to identifying parameters of solar radiation and ambient temperature using autoregressive modeling with exogenous inputs. Journal of Electrical and Electronics Engineering 2016; 11 (4): 53-58.

[25]. C. Huang, A. Bensoussan, M. Edesess and K. L Tsui. Improvement in artificial neural network-based estimation of grid connected photovoltaic power output. Renewable Energy, 97 (2016) 838-848. 